This item was submitted to Loughborough's Research Repository by the author.

Items in Figshare are protected by copyright, with all rights reserved, unless otherwise indicated.

\title{
TEM microstructural analysis of as-bonded copper ball bonds on aluminum
} metallization

PLEASE CITE THE PUBLISHED VERSION

PUBLISHER

(c) IEEE

VERSION

VoR (Version of Record)

LICENCE

CC BY-NC-ND 4.0

\section{REPOSITORY RECORD}

Xu, Hui, Changqing Liu, Vadim V. Silberschmidt, and Zhong Chen. 2019. "TEM Microstructural Analysis of Asbonded Copper Ball Bonds on Aluminum Metallization”. figshare. https://hdl.handle.net/2134/5333. 
This item was submitted to Loughborough's Institutional Repository (https://dspace.lboro.ac.uk/) by the author and is made available under the following Creative Commons Licence conditions.

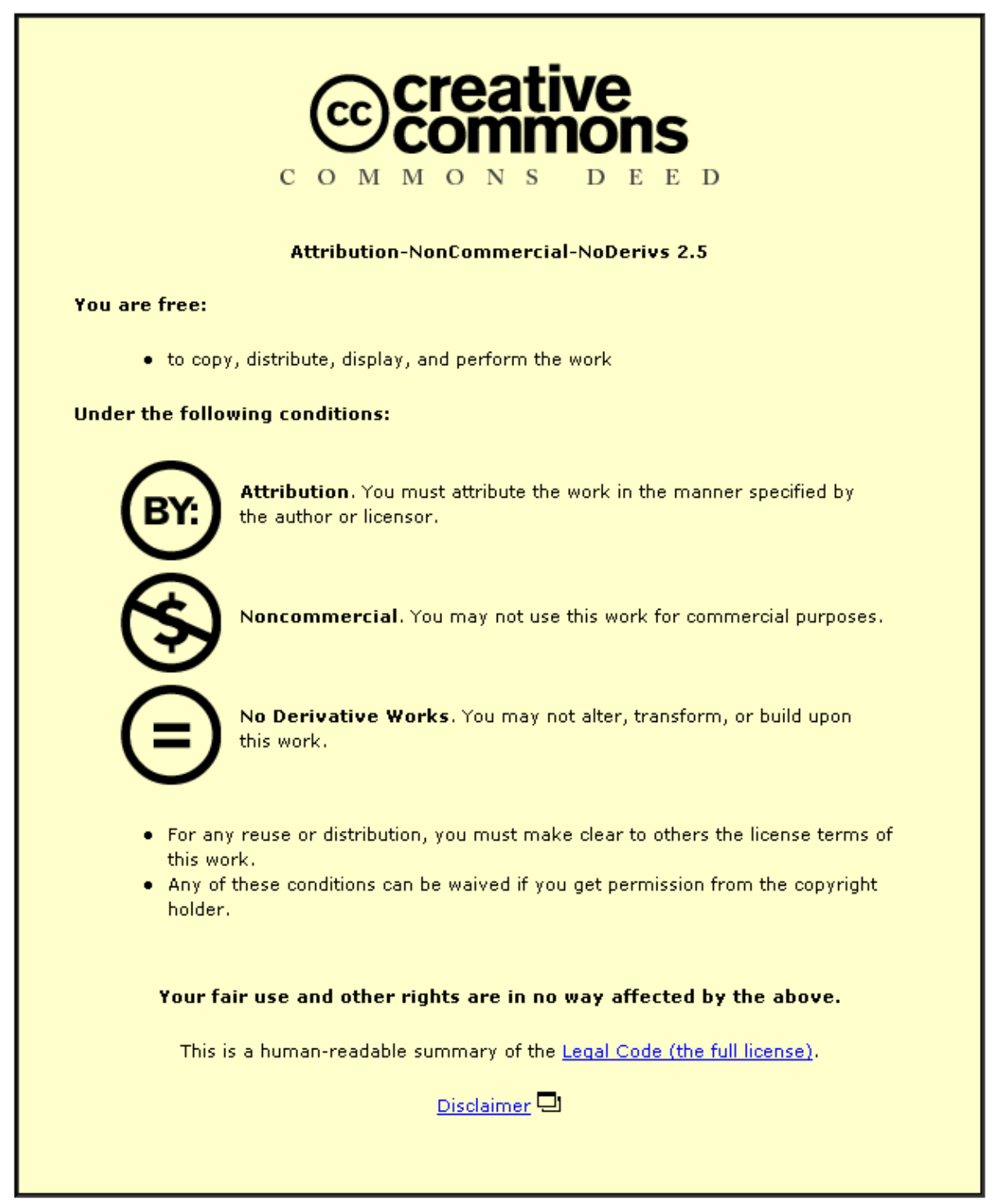

For the full text of this licence, please go to: http://creativecommons.org/licenses/by-nc-nd/2.5/ 


\title{
TEM Microstructural Analysis of As-bonded Copper Ball Bonds on Aluminum Metallization
}

\author{
Hui Xu ${ }^{1}$, Changqing Liu ${ }^{1}$, Vadim V. Silberschmidt ${ }^{1}$, Zhong Chen ${ }^{2}$ \\ ${ }^{1}$ Wolfson School of Mechanical and Manufacturing Engineering, Loughborough University, Loughborough, LE11 3TU, UK \\ ${ }^{2}$ School of Materials Science and Engineering, Nanyang Technological University, Nanyang Avenue, Singapore 639798, \\ Singapore \\ E-mail: H.Xu3@lboro.ac.uk, Phone: +44-1509-227684
}

\begin{abstract}
In this study, the nano-scale interfacial details of ultrasonic copper ball bonding to an aluminum metallization in the asbonded states were investigated using high resolution scanning/transmission electron microscopy with energy dispersive spectroscopy. Our results showed that ultrasonic vibration swept aluminum oxide and copper oxide in some regions of contacting surface, where an approximate $20 \mathrm{~nm}$ $\mathrm{Cu}-\mathrm{Al}$ intermetallics (i.e. $\mathrm{CuAl}_{2}$ ) formed. In the regions where oxide remained, aluminum oxide layer connected with copper oxides layer. No nano-level voids or gaps were observed at the central area of the interface, including the regions with oxide. Calculation of interfacial temperature showed that the ultrasonic vibration increased the flash temperature up to 465 ${ }^{\circ} \mathrm{C}$ which was believed to improve the interdiffusion for the formation of $\mathrm{Cu}-\mathrm{Al}$ intermetallics.
\end{abstract}

\section{Introduction}

Thermosonic copper wire-ball bonding is an absorbing interconnection technology that serves viable and cost saving alternative to thermosonic gold wire-ball bonding [1]. Its excellent mechanical and electrical characteristics make copper ball bonding attractive for high-speed, high-power devices and fine-pitch applications. There have been many studies on the effects of bonding process parameters on bondability, which was also evaluated through shear/pull tests, [2-4] and $\mathrm{Cu}-\mathrm{Al}$ interfacial evolution via thermal cycling/aging [5-7]. Also, several models were established to explain the bonding mechanism, including fretting [8] and micro-slip model [9]. Fretting mechanism was proposed by Hulst [8] who illustrated that interfacial sliding between wire and pad cleaning and heating surface was the key for bonding. Micro-slip model [9] predicted slip only existed at the periphery of the contacting interface, while two metals stick in the central regions, thus bonding was preferential at the periphery. However, all these models were lack of experimental supports as to the fundamental mechanisms. The details of atomic features at the bonding interface have not yet been observed to provide any supporting evidence.

IMCs formation and potential voids and cracks have a significant effect on the strength and reliability of the bonds. A proper amount of IMCs formation in a wire bond increases the bonding strength but its excessive growth can result in the performance degradation of the bond. It has been reported that a layer of Au-Al intermetallics was formed during bonding process for gold ball bonded on aluminum metallization, typically 200-500 $\mathrm{nm}$ thick $[10,11]$. Compared with the rapid growth of Au-Al IMCs, the growth of $\mathrm{Cu}-\mathrm{Al}$ IMCs has been suggested to be much slower [12]. SEM observation of interfaces by Wulff et al. [6] found no $\mathrm{Cu}-\mathrm{Al}$ IMCs was formed in the as-boned $\mathrm{Cu}$ - $\mathrm{Al}$ bonds. However, the conclusion was not firm due to limitations of analytical tool they used to carry out the study. Therefore, an advanced nano-level analysis tool becomes a key to ascertain interfacial metallurgical characteristic of as-bonded $\mathrm{Cu}-\mathrm{Al}$ bonds. The importance of interfacial analysis at the atomic level is necessary in order to obtain the direct evidence of a fundamental mechanism of copper thermosonic bonding.

In this paper, a $50.4 \mu \mathrm{m} 99.99 \%$ in purity copper wire was bonded on a $3 \mu \mathrm{m}$ thick Al metallization using an ASM angle 60 automatic thermosonic ball/wedge bonder with a frequency of $138 \mathrm{kHz}$. High resolution scanning/transmission electron microscopy (HR SEM/TEM) with energy dispersive spectroscopy (EDS) were conducted to ascertain the interfacial metallurgical characteristics of as-bonded $\mathrm{Cu}-\mathrm{Al}$ bonds. Site-specific TEM samples were prepared using a dualbeam focused ion beam (FIB) system. The thermosonic copper ball bonding mechanism was then proposed.

\section{Experimental Procedures \\ Bonding process}

In the experiment, a $50.4 \mu \mathrm{m}$ copper wire (99.99\% purity) was bonded onto a $3 \mu \mathrm{m}$ thick Al metallization pad on a silicon chip using an ASM Eagle 60 ball/wedge automatic bonder with an ultrasonic frequency of $138 \mathrm{kHz}$.

An electronic flame-off (EFO) process was applied to produce a spherical ball as the first step of the bonding process circle. The initial copper ball was achieved with a current of $150 \mathrm{~mA}$ and a gap voltage $5500 \mathrm{~V}$ with a discharge time of 1.3 $\mathrm{ms}$. In order to prevent the copper ball from oxidation in the EFO process, a protective shielding gas of mixture $-95 \% \mathrm{~N}_{2}+$ $5 \% \mathrm{H}_{2}$ - was supplied and maintained at a flow rate of 0.8 $\mathrm{L} / \mathrm{min}$. The copper ball was then bonded to an aluminum metallization using a combination of heat, transverse ultrasonic vibration, and a normal force. The detailed bonding parameters for the copper ball bonds are shown in Table 1 after the process window was optimized by means of pull/shear tests and dimension tests.

Table 1 Optimized bonding parameters for copper ball bonds

\begin{tabular}{|c|c|}
\hline Ultrasonic power (DAC) & 90 \\
\hline Bonding force $(\mathrm{gf})$ & 110 \\
\hline Bonding time $(\mathrm{ms})$ & 28 \\
\hline Substrate temperature $\left({ }^{\circ} \mathrm{C}\right)$ & 220 \\
\hline
\end{tabular}

\section{Characterization}

The shear strength of the wire-bonds was measured using a Dage4000 shear tester, using lateral movement of a shear tool positioned $3 \mu \mathrm{m}$ above the aluminum metallization. The maximum shear value was measured by a strain gauge transducer.

A dual-beam FIB workstation was used to prepare sitespecific TEM specimens across the $\mathrm{Cu}-\mathrm{Al}$ interfacial zone. First, the mashed ball was thinned by bombardment of ion $200810^{\text {th }}$ Electronics Packaging Technology Conference 
beam, till the height from the top of the thinned ball to $\mathrm{Cu}-\mathrm{Al}$ interface was below $10 \mu \mathrm{m}$. Two holes were etched by focused ion beam, while an approximate $2 \mu \mathrm{m}$ width foil remained between them, as shown in Fig. 1. This foil was the rough TEM sample. Compared with traditional preparation methods, such as ion beam etching and electropolishing, the FIB microscope has been used as a high-resolution imaging tool. Its secondary electron images provide enhanced crystallographic contrast similar to the electron channeling contrast in SEM. Therefore, interesting zones can be located and selected accurately, making it especially suitable for the multi-interface observation in high resolution analysis. The insitu FIB lift-out technique was used to obtain these sitespecific TEM specimens. An omniprobe in-situ tungsten (W) lift-out probe was used. The $\mathrm{W}$ lift-out probe was attached to the specimen by ion beam assisted $\mathrm{Pt}$ chemical vapor deposition (CVD). The TEM specimen was then lifted out from the bulk using the $\mathrm{W}$ probe, as shown in Fig. 2. Before the specimen can be adhered to the TEM grid, a semicircular Mo TEM grid was positioned on the sample stud. A Mo grid instead of $\mathrm{Cu}$ grid which was usually used was applied to avoid $\mathrm{x}$-ray energy overlaps with $\mathrm{Cu}$ from $\mathrm{Cu}$ ball.

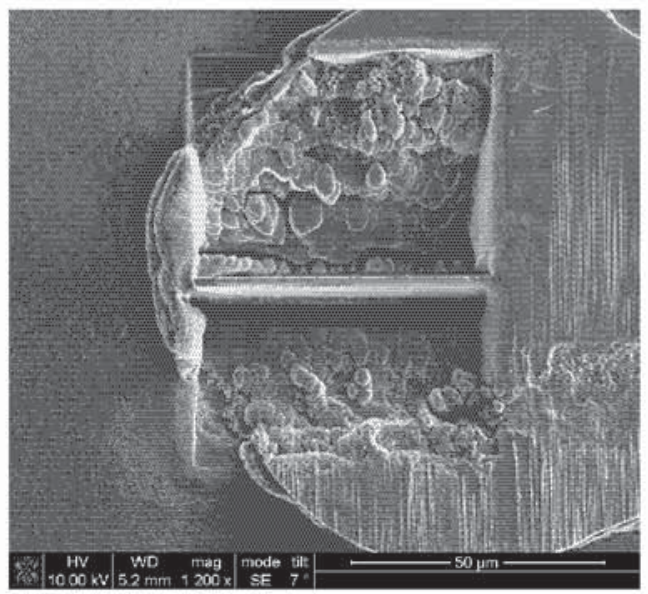

Fig. 1. Two holes were made by FIB etching after copper ball was thinned. The foil between the holes was the TEM sample, with an initial width of approx. $2 \mu \mathrm{m}$.

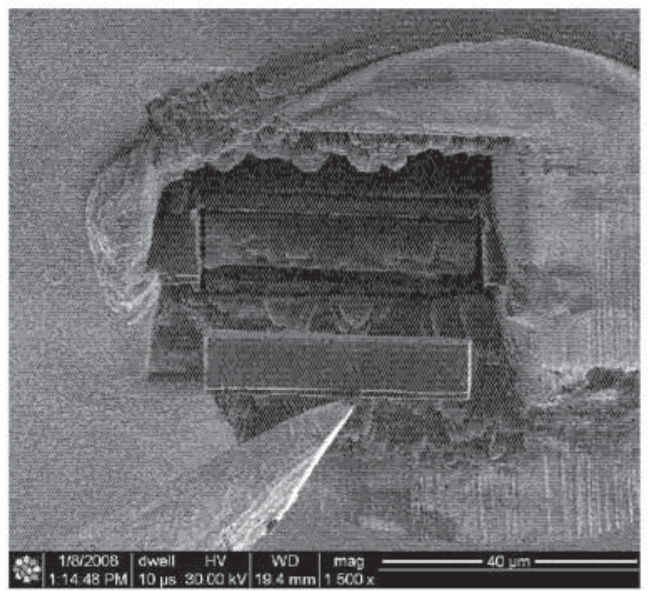

Fig. 2. The TEM specimen was lifted out from the bulk using the $\mathrm{W}$ probe.
After the sample was lifted-out, the grid was moved into the field of view. The probe was lowered and loaded onto the TEM grid, as seen in Fig. 3. Then the foil was attached to the grid using the ion beam Pt CVD. Once the specimen has been attached to the TEM grid, the in-situ $\mathrm{W}$ probe was milled free by focused ion beam. The focus ion beam with lower current was then used to thin the specimen to electron transparency $(100-200 \mathrm{~nm})$ as shown in Fig. 4. Through all the sample preparation process, the site-specific TEM samples were stress-free and contamination-free.

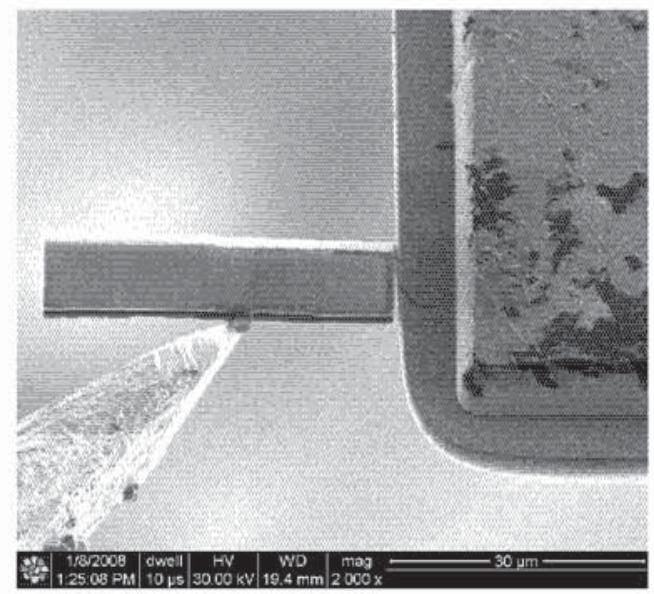

Fig. 3. TEM foil touched a Mo grid, followed by ion beam Pt CVD to make adhesion.

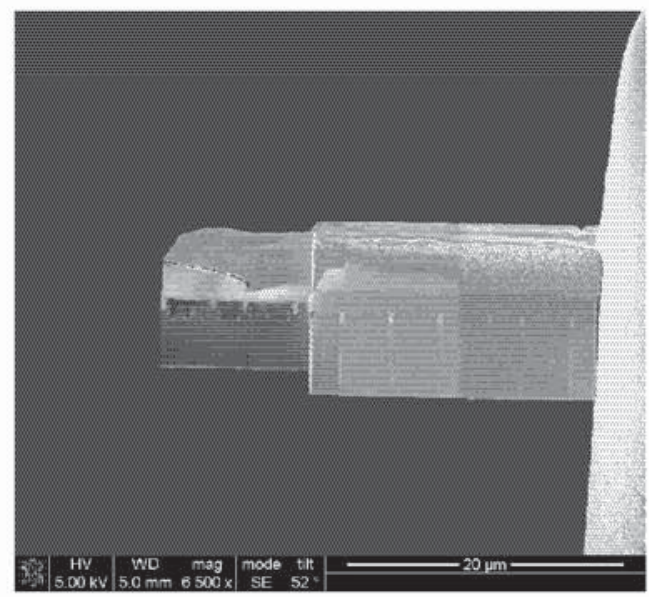

Fig. 4. TEM foil was finally thinned using focused ion beam for electron transparency, i.e. $100-200 \mathrm{~nm}$.

HRSEM was conducted to view the morphology of the interface in as-bonded $\mathrm{Cu}-\mathrm{Al}$ bonds, using the secondary electron of the double beam FIB workstation.

HRTEM analysis was done at $200 \mathrm{kV}$ using a JEOL 2100 field emission gun TEM. The resulting HR TEM images were subjected to a fast Fourier transform (FFT) analysis, so as to get the diffraction patterns. Several d-spacing values were measured from the HR TEM images using commercial software ImageJ. Phase structure can be identified by the obtained diffraction patterns and D-spacing. EDX quantification was using the mode of scanning TEM (STEM)EDX, using a $0.6 \mathrm{~nm}$ diameter electron beam.

$200810^{\text {th }}$ Electronics Packaging Technology Conference 


\section{Results}

\subsection{As-bonded Copper Bonds on Aluminum Metallization}

Bonds were subject to the thermal and electrical impact during operation service, especially at the interface. Most of the device fails as a result from the reliability eliminated by the bonding joints [13]. Fig. 5 shows typical copper ball bonds on aluminum metallization on an IC chip after thermosonic bonding interconnection with optimized parameters in this study. From the bond appearance, the bonds were well formed and there is no evident of cracking. The failure in the shear test typically occurs in the mashed copper ball rather than at the interface between the ball and the aluminum metallization pad (see Fig. 6); it typically occurs as a neck break in the pull test (see Fig. 7), indicating that the copper ball and aluminum metallization are successfully bonded together with a high bonding strength for above optimized process parameters shown in table 2 .

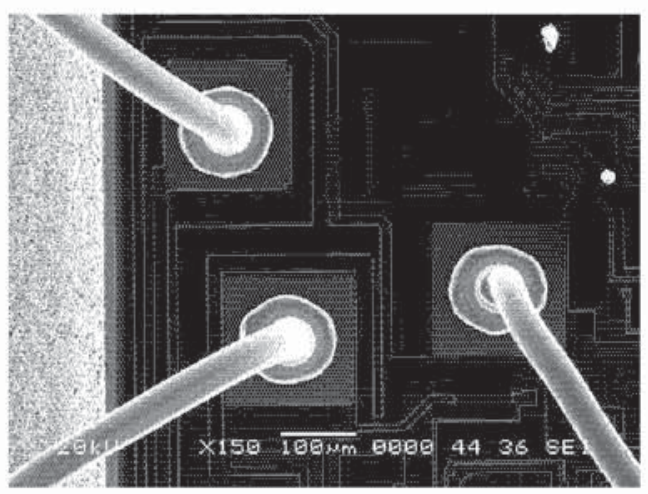

Fig. 5. SEM image of typical copper wire ball bonds on aluminum metallization on an IC by thermosonic bonding

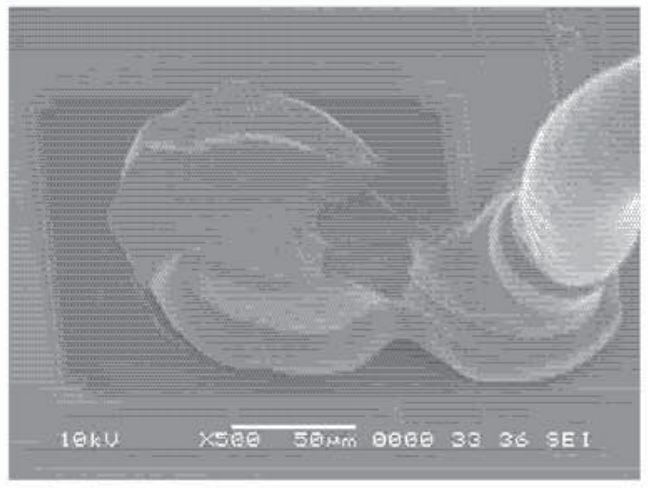

Fig. 6. Failure position in mashed copper balls after shear test showing the copper ball strongly bonded on the aluminum pad (average shear force $145 \mathrm{gf}$ )

At present, it remains unclear as to how a strong bond can be formed within such a short time (e.g. $25 \mathrm{~ms}$ ), and whether melting or sufficiently high temperature may cause IMCs or interdiffusion region at the interface leading to a strong interconnection. In order to ascertain the interfacial metallurgical characteristics of as-bonded $\mathrm{Cu}-\mathrm{Al}$ bonds, highresolution HRSEM and HRTEM with EDS are employed to provide the details at the interface.

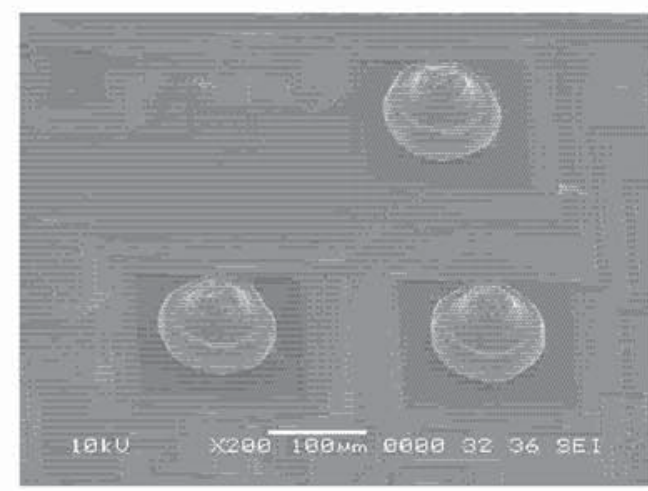

Fig. 7. Failure position in necks after pull test confirmed good bondability (average pull force 41 gf)

\subsection{Nano-scale interfacial morphology of $\mathrm{Cu}-\mathrm{Al}$ bonds}

Copper ball was successfully bonded on aluminum metallization with the optimized bonding parameters shown in Table 1. The typical interfacial morphology by SE SEM was shown in Fig. 8. The details of the highlighted area A and B in Fig. 8 are given in Fig. 9 and Fig. 10 by HRSEM, respectively.

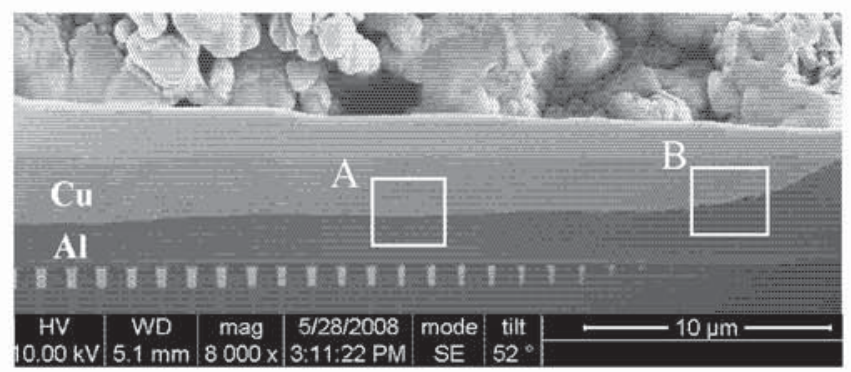

Fig. 8. Secondary electron micrograph of the $\mathrm{Cu}-\mathrm{Al}$ interface formed with optimized parameters shown in Table 1

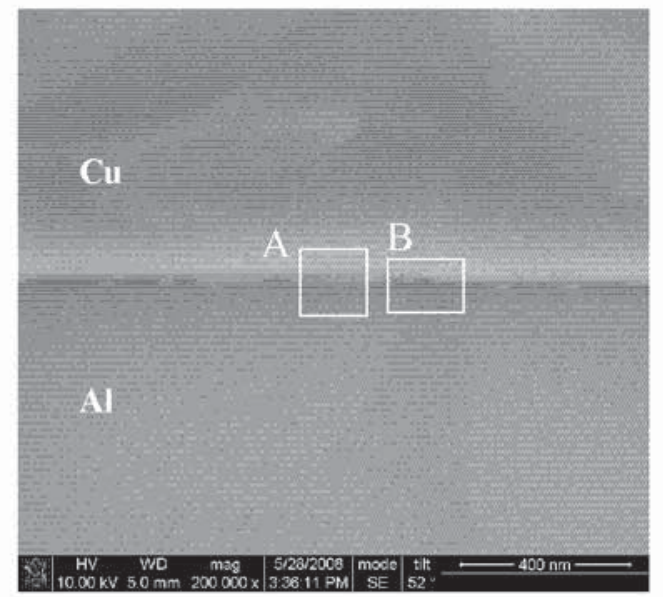

Fig. 9. Details of the highlighted area A in Fig. 8 showing some reactants were formed at some regions - not entire regions - of the $\mathrm{Cu}-\mathrm{Al}$ interface.

Fig. 9 shows that some reactants formed at some regions of the interface (e.g. area A in Fig. 9), although they did not exist in some regions (e.g. area B in Fig. 9). These reactants suggested metallurgic bonding. However, it was difficult for HRSEM to determine weather it is $\mathrm{Cu}-\mathrm{Al}$ intermetallics, solidsolution or contaminants. Identification of these reactants is needed by HRTEM-FFT as discussed in the following

$200810^{\text {th }}$ Electronics Packaging Technology Conference 
paragraphs. It is unclear if the metallurgic bonding is present at the interface where no such reactants were formed. It is expected that observing the nano features of such interface using HRTEM may provide a insight.

Fig. 10 illuminates that some micro-cracks were formed at the edge of the bonding interface. It was interesting that the crack was in some extent inside of aluminum and copper, as shown in area A and B in Fig 10, respectively. This suggested that metallurgical bonding also exists at the edge of the interface, and crack was formed after the $\mathrm{Cu}-\mathrm{Al}$ metallurgical joining due to the long-drawn ultrasonic vibration.

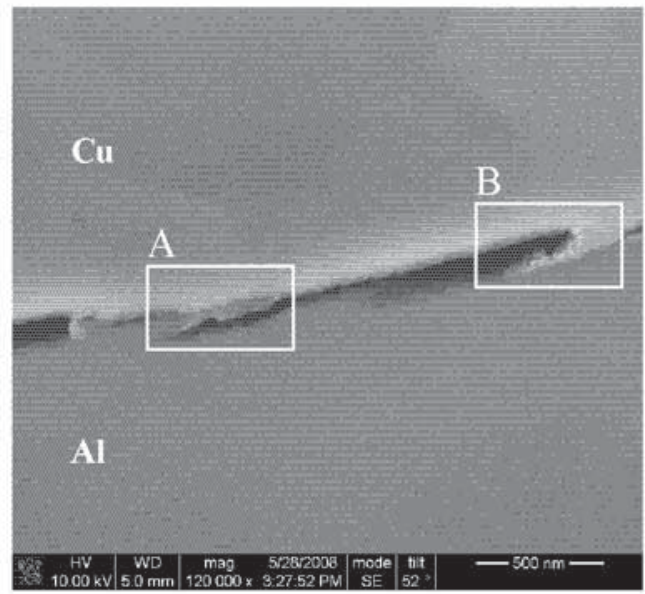

Fig. 10. Details of the highlighted area B in Fig. 8 showing micro-crack present at the edge, which was in some extent inside of aluminum and copper

Fig. 11 is a bright field (BF) diffraction contrast TEM micrograph of the interface region of a bond between a copper ball and aluminum metallization. The difference between the atomic number of $\mathrm{Cu}$ and $\mathrm{Al}$ results in large contrast changes between the $\mathrm{Al}$ and the $\mathrm{Cu}$, and in the black contrast from the $\mathrm{Cu}$. Two typical features were found at the interface, as shown in region $\mathrm{A}$ and region $\mathrm{B}$ in Fig. 11, respectively. Both of these features will be discussed in details subsequently using HRTEM.

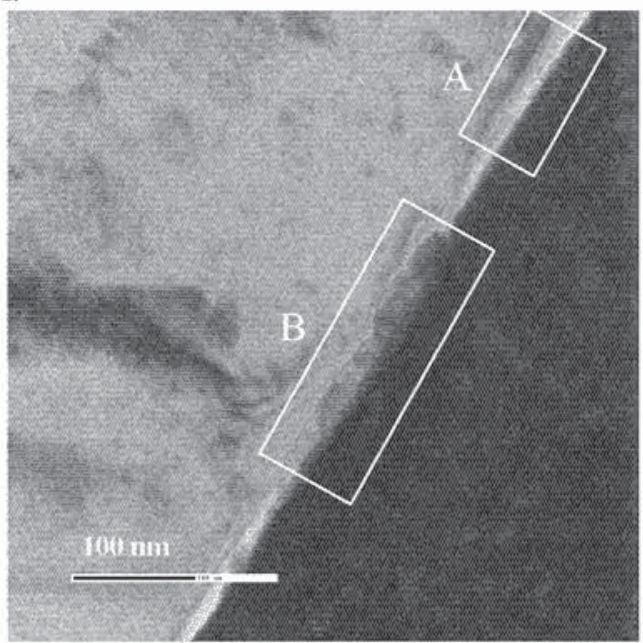

Fig. 11. BF TEM micrograph presenting the morphology of the interface region of a $\mathrm{Cu}-\mathrm{Al}$ bond. The $\mathrm{Al}$ has a white contrast, due to it's relatively low mass-thickness compared to $\mathrm{Cu}$.
The details of region A in Fig 11 were shown in Fig. 12. It is clearly shown that several layers were presented between the copper and aluminum. Layer A and layer B were amorphous phase and layer 3 was crystalline phase. In order to obtain the composition of these layers, STEM-EDX was conducted, and results were presented in Table 2, which indicated that layer $\mathrm{A}$ was aluminum oxide and layer B consists of aluminum-rich amorphous structure. The amorphous aluminum oxide layer (approximately 10-15 nm) could be the initial layer on the surface of the aluminum.

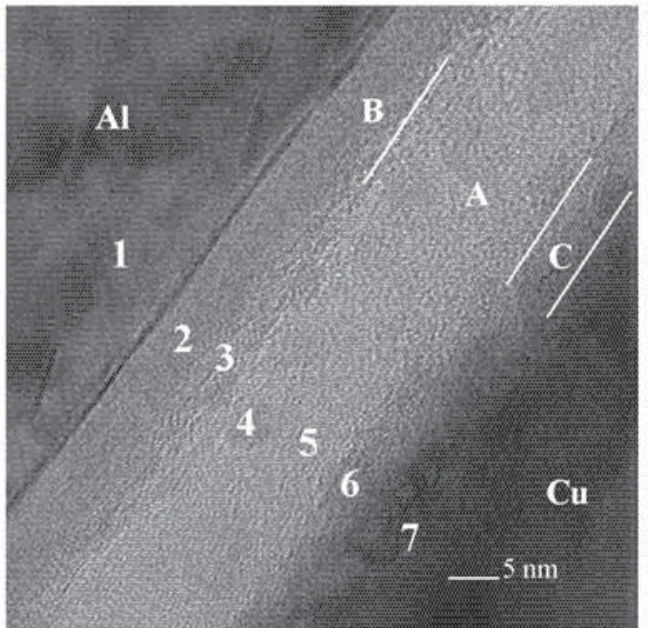

Fig. 12. Details of the highlighted region A in Fig. 11 showing multi-layers at the $\mathrm{Cu}-\mathrm{Al}$ interface

Table 2 EDS results of spots 1-7 in Fig. 12

\begin{tabular}{|c|c|c|c|}
\hline Spots & OK At $\%$ & AlK At $\%$ & CuK At $\%$ \\
\hline 1 & 4.8 & 93.1 & 2.1 \\
\hline 2 & 11.2 & 87.4 & 1.4 \\
\hline 3 & 55.3 & 43.0 & 1.8 \\
\hline 4 & 42.5 & 50.1 & 7.4 \\
\hline 5 & 46.5 & 48.0 & 5.4 \\
\hline 6 & 44.8 & 11.7 & 43.5 \\
\hline 7 & 6.3 & 3.3 & 90.4 \\
\hline
\end{tabular}

Fig. 13 shows the details of region $\mathrm{A}$ in Fig. 12. The diffraction pattern and lattice orientation of region $\mathrm{A}$ and region $\mathrm{B}$ were reconstructed from HR TEM image using FFT, as shown on the top right corner and top left corner, respectively, in Fig. 13. The values of spacing-d were measured using image analysis software ImageJ, and measured d-spacing $=0.209 \mathrm{~nm}, 0.210 \mathrm{~nm}$ and $0.181 \mathrm{~nm}$ for region $A$ and d-spacing $=0.269 \mathrm{~nm}, 0.260 \mathrm{~nm}$ and $0.231 \mathrm{~nm}$ for region $\mathrm{B}$. Thus, the crystalline phase in region $\mathrm{A}$ and region $\mathrm{B}$ were identified to be copper (lattice constant $\mathrm{a}=$ $0.362 \mathrm{~nm}$ ) and copper oxide (i.e. $\mathrm{CuO}$ ) (lattice constants $\mathrm{a}=$ $0.465 \mathrm{~nm}, \mathrm{~b}=0.341 \mathrm{~nm}$ and $\mathrm{c}=0.511 \mathrm{~nm})$, respectively. Those results were consistent with that obtained by STEMEDX as shown in Table 2 . The copper oxide was thought to be the initial layer formed during copper ball formation when copper was melted by electronic sparking. This copper oxide grew preferentially along the $\left[\begin{array}{lll}0 & 0 & 1\end{array}\right]$ and was approximate 3 $\mathrm{nm}$ in thickness. It was surprising that the amorphous 
aluminum oxide layer and copper oxide layer connected very well at atomic scale.

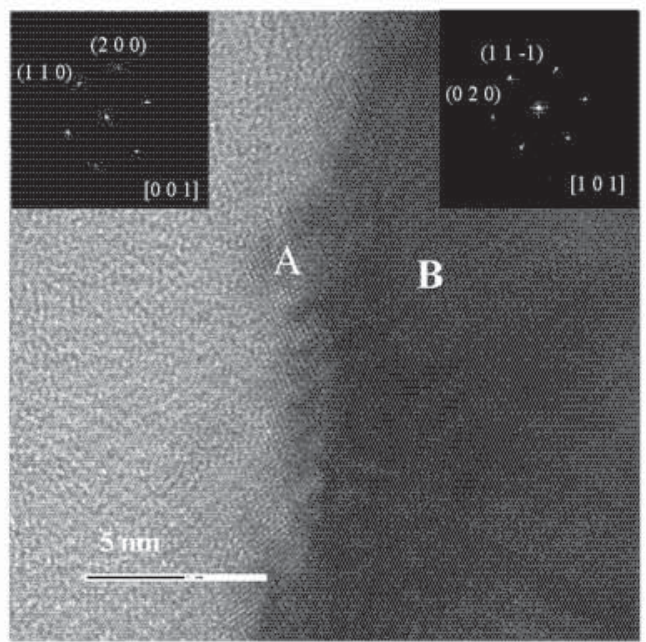

Fig. 13. Bright field HRTEM and lattice images of interface between amorphous aluminum oxide layer and crystalline phase. It was confirmed region $\mathrm{A}$ was copper and region $\mathrm{B}$ was $\mathrm{CuO}$.

The details of another feature at the interface in region B of Fig. 11, was analyzed by HRTEM, the results are shown in Fig. 14. The thick amorphous aluminum oxide layer did not exist; in such a case, one approximate $20 \mathrm{~nm}$ crystalline layer, labeled as A, was found between the copper and aluminum.

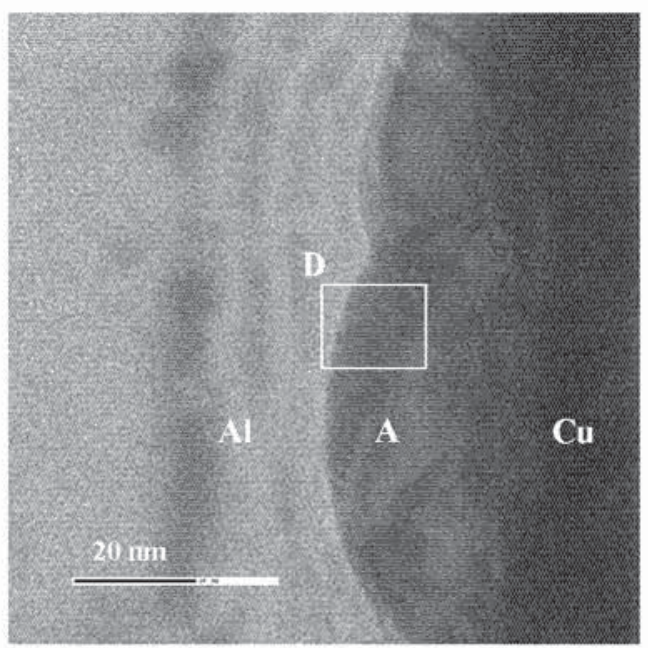

Fig. 14. Details of region B in Fig 11 showing an approx. 20 $\mathrm{nm}$ crystalline layer present between the aluminum and copper, and the thick amorphous aluminum oxide disappeared.

Further study on region D of Fig 14 by HRTEM, the results are shown in Fig. 15. Analysis of this HRTEM image and FFT reconstruction on region A confirmed the formation of $\mathrm{CuAl}_{2}$, with lattice constants $\mathrm{a}=0.6067 \mathrm{~nm}$ and $\mathrm{c}=0.4877$ $\mathrm{nm}$, that grew preferentially along the $\left[\begin{array}{lll}2 & 1 & 0\end{array}\right]$. The diffraction pattern and lattice orientation was shown on the top right corner in Fig. 15, and measure d-spacing $=0.239 \mathrm{~nm}, 0.230$ $\mathrm{nm}$ and $0.229 \mathrm{~nm}$. Region B has the same diffraction pattern as region $\mathrm{A}$, and measured $\mathrm{d}$-spacing were $0.242 \mathrm{~nm}, 0.233$ $\mathrm{nm}$ and $0.231 \mathrm{~nm}$, thus this represents the $\mathrm{CuAl}_{2}$ in region $\mathrm{B}$ with a possible slightly aluminum solute.

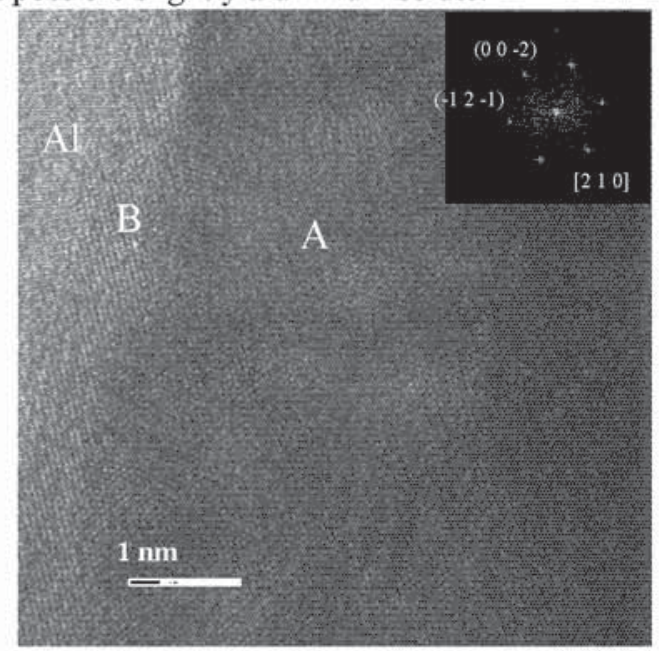

Fig. 15. Zoom-in image of region D in Fig. 14. HRTEM-FFT confirmed the crystalline phase between aluminum and copper was $\mathrm{CuAl}_{2}$.

\section{Discussion}

Strong $\mathrm{Cu}-\mathrm{Al}$ bond was made through thermosonic bonding process which was implemented within $25 \mathrm{~ms}$ with the application of ultrasonic vibration for each bond. HRSEM provided overview of interfacial morphology of as-bonded $\mathrm{Cu}-\mathrm{Al}$ bonds. Further study by HRTEM elaborated the nanofeatures of $\mathrm{Cu}-\mathrm{Al}$ interface. Two typical locations were found at the interface, as shown in Fig. 12 and Fig. 14, respectively. One consists of aluminum oxide layer and copper oxide layer, another one was free of oxide layer. As aluminum oxide and copper oxide were the initial layers at the surface of aluminum and copper, respectively, it suggested that the ultrasonic vibration swept some regions of the interface, while in some other regions, the oxides remained there.

The real contacting surfaces are rough [14], thus, the wear is preferential at the tips of asperities. In the valley of the surface, aluminum oxide and copper oxide can remain. However, we found aluminum oxide and copper oxide still connected at atomic scale.

At the regions where oxides were cleaned by ultrasonic vibration, a layer of $\mathrm{Cu}-\mathrm{Al}$ intermetallics was formed and it was confirmed that this first nucleation of intermetallics was $\mathrm{CuAl}_{2}$. The thickness of this intermetallics layer was approximate $20 \mathrm{~nm}$. Previous studies on the $\mathrm{Cu}-\mathrm{Al}$ bonds showed that no $\mathrm{Cu}-\mathrm{Al}$ intermetallics formed at the as-bonded state [6], because of the small size of the intermetallics, which have been observed in our study by HR TEM and at the relative high resolution.

It has been reported that the $\mathrm{Cu}-\mathrm{Al}$ intermetallics growth at the $\mathrm{Cu}-\mathrm{Al}$ bond followed the parabolic law during thermal aging $[5,12]$. Assuming that $\mathrm{Cu}-\mathrm{Al}$ intermetallics growth during bonding process was diffusion controlled, obeying by $x=(D t)^{1 / 2}$

$D=D_{0} \exp \left(-\frac{Q}{R T}\right)$

where $x$ is a IMC thickness at time $t, D$ is the growth rate constant, $D_{0}$ is a pre-factor, $Q$ is the activation energy, $R=$ $200810^{\text {th }}$ Electronics Packaging Technology Conference 
$8.314 \mathrm{~J} /(\mathrm{K} \times \mathrm{mol})$ is the Boltzmann constant, and $T$ is the absolute temperature.

Literature data [5] for $\mathrm{Cu}-\mathrm{Al}$ intermetallics growth lead to $Q=97.1 \mathrm{~kJ} / \mathrm{mol}$; with $x=20 \mathrm{~nm}$ and $t=0.025 \mathrm{~s}$ for bonding process, the interfacial temperature can be calculated to be 465 ${ }^{\circ} \mathrm{C}$. The previous study of in-situ measurement of the interfacial temperature using K-type thin film thermocouples showed the measured temperature was $320^{\circ} \mathrm{C}$ [15], and the authors supposed that the real temperature on some spots or regions should be higher due to the big sensor used $(20 \mu \mathrm{m}$ in width) and the measured temperature was an average temperature. Thus, our calculated temperature of $465{ }^{\circ} \mathrm{C}$ for the regions with intermetallics where were the tips of asperities is reasonable. Therefore, the ultrasonic vibration not only cleaned the contact surface, but also increased the interfacial temperature, which improved atomic interdiffusion between $\mathrm{Cu}$ and $\mathrm{Al}$.

To summarize, thermosonic copper ball bonding mechanism can be described as follows: ultrasonic vibration sweeps aluminum oxide and copper oxide locally to enable $\mathrm{Cu} / \mathrm{Al}$ contacts with the application of bonding pressure. At such regions where oxide is removed, pure metals expose and contact, and atomic interdiffusion proceeds. The flash temperature at these regions increases up to $465{ }^{\circ} \mathrm{C}$ due to the cyclic relative motion induced by ultrasonic vibration. As a result, a layer of approximate $20 \mathrm{~nm} \mathrm{Cu}-\mathrm{Al}$ intermetallics (i.e. $\left.\mathrm{CuAl}_{2}\right)$ are formed at the $\mathrm{Cu} / \mathrm{Al}$ contact areas. The formation of intermetallics greatly improves bonding strength. At the regions where oxide remains, no solid-solution or intermetallics present, however, the aluminum oxide and copper oxide still remains contact and free of voids or gaps between them.

\section{Conclusions}

Nano-scale interfacial characteristics of as-bonded $\mathrm{Cu}-\mathrm{Al}$ bonds were observed by HR TEM which provided the direct evidence of a fundamental mechanism of thermosonic copper ball bonding.

(1) Ultrasonic vibration swept aluminum oxide and copper oxide in some regions of contacting surface; while in other regions, oxides remained.

(2) No voids or gaps were found at the interface, including the regions with and without oxide, except at the edge. At the regions with oxide, aluminum oxide and copper oxide remains connected.

(3) In the cleaned regions, an approximate $20 \mathrm{~nm} \mathrm{Cu}-\mathrm{Al}$ intermetallics was formed. The formation of the intermetallics improved the bonding strength. The first nucleated intermetallics was identified to be $\mathrm{CuAl}_{2}$.

(4) Calculation of interfacial temperature showed that the ultrasonic vibration increased the flash temperature at the regions without oxide up to $465{ }^{\circ} \mathrm{C}$ which improved the diffusivity for the formation of intermetallics.

\section{Acknowledgments}

This paper is an output from the PMI2 Project funded by the UK Department for Innovation, Universities and Skills (DIUS) for the benefit of the Singapore Higher Education Sector and the UK Higher Education Sector.
Authors would like to acknowledge Associate Prof. Tim White, Mr. Stevin Snellius Pramana, Mr. Shaode Zhu and Mr. Honghui Wang for their advices and experimental assistance.

\section{References}

1. Valery, M. D., "Electrochemical Aspects of New Materials and Technologies in Microelectronics," Microelectronic Engineering, Vol. 70, No. 2 (2003), pp. 461-469.

2. $\mathrm{Xu}, \mathrm{H}$. et al, "Effects of Process Parameters on Bondability in Thermosonic Copper Ball Bonding," Proc $46^{\text {th }}$ Electronic Components and Technology Conf, Orlando, FL, May. 2008, pp. 1424-1430.

3. Ding, Y. et al, "Effects of Bonding Force on Contact Pressure and Frictional Energy in Wire Bonding," Microelectronics Reliability, Vol. 46, No. 7 (2006), pp. 1101-1112.

4. Han, L. et al, "Bondability Window and Power Input for Wire Bonding," Microelectronics Reliability, Vol. 46, No.2-4 (2006), pp. 610-615.

5. Xu, H. et al, "Growth behavior of intermetallic compound on bonding joint of $\mathrm{Cu}$ wire on $\mathrm{Al}$ alloy pad during thermal aging," Acta Metallurgica Sinica, Vol. 43, No. 2 (2007), pp. 125-130.

6. Wulff, F. W., et al, "Intermetallic Growth in Copper and Gold Ball Bonds on Aluminum Metallisation," $6^{\text {th }}$ Electronics Packaging Technology Conference, Singapore, December. 2004, pp.348-353

7. Murali, S., et al, "Fundamentals of Thermo-sonic Copper Wire Bonding in Microelectronics Packaging," Journal of Materials Science, Vol. 42, No. 2 (2007), pp. 615-623.

8. Hulst, A. P., "Ultrasonic Bonding of Insulated Wire," Welding Journal, Vol. 57, No. 2 (1978), pp. 19-25.

9. Mindlin, R. D. et al, "Effects of an Oscillating Tangential Force on the Contact Surfaces of Elastic Spheres," Journal of Applied Mechanics-Transactions of the ASME, Vol.18, No. 3 (1951), pp. 331-331.

10. 10.Breach, C. D., Wulff, F. "New Oservations on Intermetallic Compound Formation in Gold Ball Bonds: General Growth Patterns and Identification of Two Forms of $\mathrm{Au}_{4} \mathrm{Al}$," Microelectronics Reliability, Vol. 44, No. 6 (2004), pp. 973-981

11. 11.Karpel, A., et at, "TEM microstructural analysis of AsBonded Al-Au wire-bonds," Journal of Materials Science, Vol. 42, No. 7 (2007), pp. 2334-2346.

12. 12.Kim, H., "Effects of $\mathrm{Cu} / \mathrm{Al}$ Intermetallic Compound (IMC) on Copper Wire and Aluminum Pad Bondability," IEEE Transactions on Components and Packaging Technologies, Vol. 26, No. 2 (2003), pp. 367-374.

13. Harman, G. G., Wire Bonding in Microelectronics, Materials, Processes, Reliability, and Yield. Second Edition. McGraw-Hill (New York; London, 1998).

14. Pugliese, G., et al, "Rough contacts between actual engineering surfaces - Part II. Contact mechanics," Wear, Vol. 264, No. 11-12 (2008), pp. 1116-1128.

15. 15.Ho, J., et al, "Thin film thermal sensor for real time measurement of contact temperature during ultrasonic wire bonding process," Sensors and Actuators A: Physical, Vol. 111, No. 2-3 (2004), pp. 188-195. 